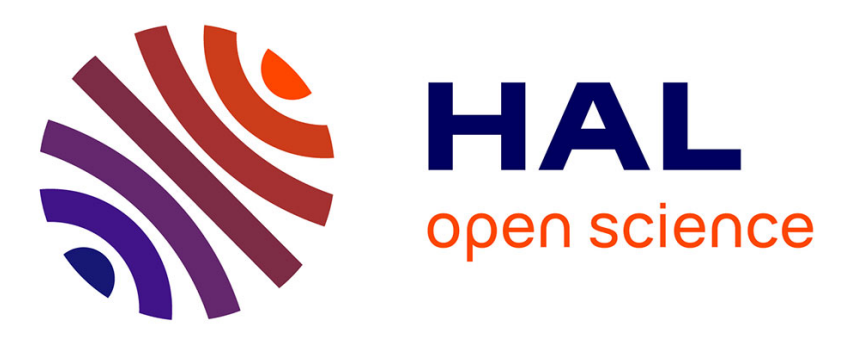

\title{
Circulating PCSK9 levels are not associated with the conversion to type 2 diabetes
}

Stéphane Ramin-Mangata, Matthieu Wargny, Matthieu Pichelin, Cedric Le

May, Aurélie Thédrez, Valentin Blanchard, Brice Nativel, Raul Santos, Isabela

Benseñor, Paulo Lotufo, et al.

\section{To cite this version:}

Stéphane Ramin-Mangata, Matthieu Wargny, Matthieu Pichelin, Cedric Le May, Aurélie Thédrez, et al.. Circulating PCSK9 levels are not associated with the conversion to type 2 diabetes. Atherosclerosis, 2020, 293, pp.49-56. 10.1016/j.atherosclerosis.2019.11.027 . hal-03013257

\section{HAL Id: hal-03013257 https://hal.science/hal-03013257}

Submitted on 6 Jan 2021

HAL is a multi-disciplinary open access archive for the deposit and dissemination of scientific research documents, whether they are published or not. The documents may come from teaching and research institutions in France or abroad, or from public or private research centers.
L'archive ouverte pluridisciplinaire HAL, est destinée au dépôt et à la diffusion de documents scientifiques de niveau recherche, publiés ou non, émanant des établissements d'enseignement et de recherche français ou étrangers, des laboratoires publics ou privés. 


\section{Circulating PCSK9 levels are not associated with the conversion to type 2 diabetes}

Authors: Stéphane Ramin-Mangata*a, Matthieu Wargny*b,c,d ${ }^{*}$ Matthieu Pichelin ${ }^{\text {b,c }}$, Cédric Le May $^{\mathrm{b}}$, Aurélie Thedrez ${ }^{\mathrm{b}}$, Valentin Blanchard ${ }^{\mathrm{a}}$, Brice Nativel ${ }^{\mathrm{a}}$, Raul D. Santos ${ }^{\mathrm{e}, \mathrm{f}, \mathrm{g}}$, Isabela M Bensenor $^{\mathrm{g}}$, Paulo A Lotufo ${ }^{\mathrm{g}}$, Gilles Lambert ${ }^{\mathrm{a} \#}$, Bertrand Cariou ${ }^{\mathrm{b}, \mathrm{ct}}$.

*Co-first authors; ${ }^{*}$ Co-last authors

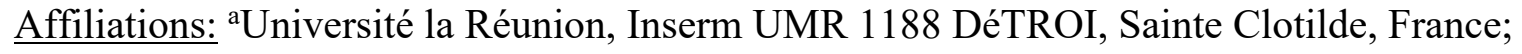

${ }^{b}$ L'institut du thorax, INSERM, CNRS, UNIV Nantes, Nantes, France;

'L'institut du thorax, Department of Endocrinology, CIC 1413 INSERM, CHU Nantes, Nantes, France;

${ }^{\mathrm{d}} \mathrm{CHU}$ de Nantes, INSERM, CIC 1413, Pôle Hospitalo-Universitaire 11: Santé Publique, Clinique des Données, Nantes, F-44093 France;

écipid Clinic Heart Institute (InCor), University of Sao Paulo Medical School Hospital, São Paulo, Brazil;

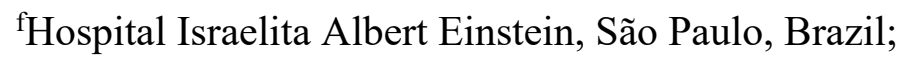

gCenter of Clinical and Epidemiologic Research, University of São Paulo, São Paulo, Brazil.

Corresponding Authors:

Pr. Gilles Lambert, Inserm UMR 1188 DéTROI, Plateforme CYROI, 2 Rue Maxime Rivière, 97490 Sainte Clotilde, France. Tel : + 262692437708 ; E-mail: gilles.lambert@univreunion.fr

\& Pr Bertrand Cariou, Clinique d'Endocrinologie, Hôpital Guillaume \& René Laennec, Boulevard Jacques Monod, Saint-Herblain, 44093 Nantes Cedex 1, France. Tel: + 3325348 27 07; Fax: + 332534827 08; E-mail: bertrand.cariou@,univ-nantes.fr

KEYWORDS: PCSK9, PCSK9 inhibition, new onset diabetes, type 2 diabetes

Total word count (including tables and figure legends): 3927

Number of tables and figures : 4 
ABSTRACT (Word count 250)

Background and aims - PCSK9 is an endogenous inhibitor of LDL receptor pathway. Recently, Mendelian randomization studies have raised a doubt about the diabetogenic risk of PCSK9 inhibitors. Here, we assessed the relationship between plasma PCSK9 levels and the risk of new onset diabetes (NOD).

Methods - Fasting plasma PCSK9 levels were measured at baseline by ELISA in subjects without lipid lowering treatment in IT-DIAB $(n=233$ patients with prediabetes, follow-up 5 years) and ELSA-Brasil ( $\mathrm{n}=1,751 ; 27.5 \%$ with prediabetes, follow-up 4 years $)$ prospective cohorts. The primary outcome in both studies was the incidence of NOD. The association of NOD with plasma PCSK9 levels was studied using multivariate Cox models.

Results - Plasma PCSK9 levels were not significantly associated with NOD in IT-DIAB (HR (+1SD) 0.96, CI I5\% $\left._{0}[0.76 ; 1.21]\right)$ and ELSA-Brasil (OR (+1SD) 1.13 [0.89; 1.42]). In ELSABrasil, a significant positive association between PCSK9 and worsening of glucose homeostasis, including the progression from normoglycemia to prediabetes, was found (OR (+1SD) $1.17[1.04 ; 1.30], P=0.0074)$. Plasma PCSK9 concentration was also positively associated with the change in fasting plasma glucose between the first and second visit in ELSA-Brasil $\left(\beta=0.053, \mathrm{CI}_{95 \%}[0.006 ; 0.10], P=0.026\right)$. Plasma PCSK9 levels positively correlated with total cholesterol in IT-DIAB and ELSA-Brasil, but not with glucose homeostasis parameters, except for a positive correlation with HOMA-IR in ELSA-Brasil.

Conclusions - Plasma PCSK9 levels were not significantly associated with NOD risk in longitudinal analyses. These data suggest that inhibition of the PCSK9 extra-cellular pathway should not be deleterious for glucose homeostasis. 


\section{INTRODUCTION}

Recent studies have shown an inverse relationship between low-density lipoprotein cholesterol (LDL-C) homeostasis and risk of type 2 diabetes. The first signal came from the results of metaanalyses of randomized controlled trials with statins. Despite their undisputable beneficial effects in lowering LDL-C and cardiovascular diseases, statins have shown to slightly, but significantly, increase the risk of NOD [1-5]. Next, Mendelian randomization studies indicated that loss-of-function (LOF) variants in the 3-Hydroxy-3-Methylglutaryl-CoA Reductase $(H M G C R)$ gene, the molecular target of statins, are associated with an increased risk of NOD. This suggests that the diabetogenic effect of statins is a true on-target effect operating via an up-regulation of the LDLR pathway [6]. Conversely, diabetes prevalence is twice lower in patients with familial hypercholesterolemia, compared with their non-affected relatives, with diabetes risk being maximally reduced in carriers of the most severe mutations on the LDLR [7].

Proprotein Convertase Subtilisin Kexin type 9 (PCSK9) is an endogenous inhibitor of the LDLR pathway that acts by directing the LDLR towards lysosomal degradation. Commercially available PCSK9 inhibitors (alirocumab and evolocumab) are fully human monoclonal antibodies $(\mathrm{mAb})$ that bind circulating PCSK9 and prevent its interaction with the LDLR at the cell surface, precluding LDLR intracellular degradation [8]. Since statins and PCSK9 inhibitors reduce LDL-C by increasing the abundance of the LDLR at the surface of many cell types, in particular hepatocytes $[9,10]$, a relevant question is to determine whether PCSK9 inhibitors might also increase the risk of diabetes in humans.

This hypothesis is underpinned by the observation that some PCSK9 knockout mouse models [11,12], but not all [13], display hyperglycemia, impaired glucose tolerance, and reduced insulin secretion. This deleterious effect of PCSK9-deficiency on glucose homeostasis is apparently mediated by the LDLR [12]. More importantly, Mendelian randomization studies 
showed that PCSK9 LOF variants associate with higher fasting plasma glucose (FPG) and a higher risk of diabetes [14-16]. The odds ratio for diabetes associated with HMGCR and PCSK9 LOF variants appear to be proportional to the extent of LDL-C lowering induced by those variants [16].

To gain further insights into the possibility that inhibiting PCSK9 in the plasma with PCSK9 mAb may be diabetogenic, we assessed the relationship between circulating PCSK9 levels and the risk of NOD in two longitudinal cohorts.

\section{MATERIALS AND METHODS}

\section{Study population}

The study populations belong to the IT-DIAB study (Innovation Thérapeutique Diabète, NCT01218061 \& NCT01432509) and ELSA-Brasil (Estudo Longitudinal de Saúde do Adulto, NCT02320461).

$I T-D I A B$ - Briefly, the IT-DIAB study is a 5-year prospective, observational study designed to identify new biomarkers of type 2 diabetes risk in a population with prediabetes. The population was recruited in the occupational centers of three French cities: Nantes, Saint-Nazaire and Lille. The institutional ethics committee approved the protocol, and all the reported investigations have been carried out in accordance with the principles of the Declaration of Helsinki as revised in 2008. All patients underwent a baseline visit between June 2010 and February 2013, including a medical interview, signing of the informed consent, self-administered questionnaire of diabetes risk score, physical examination (including body weight, height, waist and hip circumference measurements) and blood sampling. Patients without history of diabetes and with impaired fasting glucose (IFG; WHO criteria) were eligible for the IT-DIAB study. The main non-inclusion criteria were a history of treatment with oral anti-diabetic agents or insulin 
(with the exception of gestational diabetes), severe coagulation disorder or thrombocytopenia (platelets levels $<100,000 / \mathrm{mm}^{3}$ ), severe renal insufficiency (defined using MDRD equation as eGFR $<30 \mathrm{~mL} / \mathrm{min} .1 .73 \mathrm{~m}^{2}$ ), severe liver impairment (prothrombin ratio $<50 \%$ ), severe psychiatric disorders, alcohol abuse (estimated $>30 \mathrm{~g} /$ day), patient's opposition or inability to participate at least 5 years in the study. For the present analysis, we also secondarily excluded the population with concomitant statin therapy. Ultimately, 233 patients with at least one follow-up visit were considered for the present analysis (see the flowchart in Supplemental Figure 1).

ELSA-Brasil - The ELSA-Brasil study design and cohort profile have been published elsewhere $[17,18]$. Briefly, it is a cohort of 15,105 men and women apparently healthy active and retired civil servants living in six Brazilian cities (Belo Horizonte, Porto Alegre, Rio de Janeiro, Salvador, Sao Paulo, and Vitoria), aged between 35 and 74 years at baseline. Information on sociodemographic, clinical history, family history of diseases, lifestyle factors, mental health, cognitive status, and occupational exposure was assessed from August 2008 to December 2010. Anthropometric measurements and laboratory and imaging tests were also obtained. The study was conducted in accordance with the Declaration of Helsinki and was approved by the local institutional review boards. All participants signed the informed consent before enrollment. Participants enrolled in the Sao Paulo site (5060 persons in total) without diabetes (noninclusion criteria: FPG $\geq 126 \mathrm{mg} / \mathrm{dL}$ and/or 2 -hour post-load glucose $\geq 200 \mathrm{mg} / \mathrm{dL}$ and/or history of treatment with oral anti-diabetic agents or insulin), without cardiovascular, renal or hepatic diseases (non-inclusion criteria: self-reported history of medical diagnosis of these pathologies), and who did not report prescription of lipid-lowering agents, were eligible for this ancillary study. We randomly selected 1751 eligible participants fulfilling the inclusion criteria for subsequent PCSK9 plasma concentrations measurements, corresponding to a third of participants enrolled in the Sao Paulo site. 


\section{Biochemical analyses}

$I T-D I A B$ - During the baseline visit, peripheral venous blood samples were obtained in the morning after an overnight fast for biological analysis and the constitution of a biocollection. Standard biological analyses included FPG, A1C, and lipid profile (direct measurements of total cholesterol (TC), high-density lipoprotein cholesterol (HDL-C), and triglycerides (TG); LDL$\mathrm{C}$ was calculated using the Friedewald equation and non-HDL-C was calculated as TC minus HDL-C). Frozen heparinized plasma was used for insulin measurement by electrochemiluminescent enzyme immunoassay (ECLIA) using the Cobas e-automated clinical analyzer system (Roche Diagnostics, Meylan, France). Plasma high molecular weight (HMW) adiponectin levels were measured by ECLIA on an automated clinical analyzer system Lumipulse G600 (Fujirebio, Les Ulis, France). Homeostasis model assessment of insulin resistance (HOMA-IR) was defined according to the equation proposed by Matthews et al [19]. ELSA-Brasil - A 12-hour fasting blood sample was drawn in the morning soon after arrival at the research clinic, following standardized procedures for samples collection and processing. A standardized $75 \mathrm{~g}$ oral glucose tolerance test (OGTT) was performed in all participants without known diabetes utilizing an anhydrous glucose solution. For measurement of fasting and postload glucose we used the hexokinase method (ADVIA 1200, Siemens); for fasting and postload insulin, an immunoenzymatic assay; for A1C, high-pressure liquid chromatography. TC, HDL-C and TG were measured with enzymatic colorimetric assays (ADVIA Chemistry). LDL$\mathrm{C}$ was calculated using the Friedewald equation. When TG were $\geq 400 \mathrm{mg} / \mathrm{dL}$, LDL-C was measured directly with an enzymatic colorimetric assay (ADVIA Chemistry).

PCSK9 Assays - Total PCSK9 plasma concentrations were determined using the Quantikine SPC900 ELISA kit (R\&D Systems, Lille, France) [20]. Briefly, plasma samples were diluted 1:20 in the calibrator diluent onto ELISA plates and incubated for $2 \mathrm{hrs}$ on a plate shaker at 
450rpm. Wells were rinsed with wash buffer using an automated Hydroflex TECAN microplate washer. The detection HRP-conjugated antibody was added to each well and plates were incubated for $2 \mathrm{hrs}$ at $450 \mathrm{rpm}$. Wells were rinsed. The TMB substrate solution was added to each well and plates were further incubated in the dark for 30 minutes at 450rpm. Reactions were stopped by the addition of $0.2 \mathrm{~N}$ acid sulphuric solution. Absorbance was read at $450 \mathrm{~nm}$ with reference at $540 \mathrm{~nm}$ on an Infinite 200 pro TECAN plate-reader. These measurements were performed by the same experimentator (SR-M), on the same site and using the same materials for both cohorts.

\section{Follow-up and conversion to new onset diabetes}

IT-DIAB - The end of the follow-up occurred at the fifth yearly visit, or prematurely if the patient met one of the following criteria: patient's withdrawal or loss to follow-up, inappropriate prescription of anti-diabetic agent, bariatric surgery or death. NOD was defined by a FPG value $\geq 126 \mathrm{mg} / \mathrm{dL}$ and/or a plasma glucose $\geq 200 \mathrm{mg} / \mathrm{dL}$ after 2-hour OGTT.

ELSA-Brasil - In ELSA-Brasil, 2-hour OGTT was performed for all patients both at baseline and at 4-year visit. Diabetes status was classified as diabetes, prediabetes or normal glucose levels. NOD was defined as a FPG value $\geq 126 \mathrm{mg} / \mathrm{dL}$ or a plasma glucose $\geq 200 \mathrm{mg} / \mathrm{dL}$ after 2-hour OGTT. Prediabetes was defined as no NOD and either FPG value between 110-125 $\mathrm{mg} / \mathrm{dL}$ or a plasma glucose between 140 and $199 \mathrm{mg} / \mathrm{dL}$ after 2-hour OGTT. Normal glucose level was defined as neither NOD nor prediabetes. Finally, the worsening of glucose homeostasis was defined as a shift between baseline and 4-year visit, either from normal glucose level to prediabetes or NOD, or from prediabetes to NOD.

\section{Statistical analyses}


Baseline categorical parameters are presented using frequencies (percentages), continuous parameters are presented using mean $\pm \mathrm{SD}$ or median $\left(25^{\text {th }}-75^{\text {th }}\right.$ quartiles $)$ in case of a skewed distribution. The correlation between plasma PCSK9 levels and the other parameters is expressed by the corresponding Spearman's rank coefficients. We analysed follow-up data through two outcomes: the incidence of NOD and the change in FPG. In IT-DIAB, the incidence of NOD was examined by drawing the Kaplan-Meier curves according to quartiles of plasma PCSK9 level. A Cox model was used to determine the association between plasma PCSK9 levels (as a continuous parameter) and the incidence of NOD, before and after adjustment for classical risk factors retained after stepwise selection, such as age at baseline, sex, waist circumference, FPG, TG, LDL-C, HDL-C and adiponectin. For ELSA-Brasil, a logistic regression model was used to assess the relationship between baseline PCSK9 and the incidence of NOD during the four-year visit, adjusted for the same parameter as the above Cox model, except for adiponectin that was not measured in this population.

In both cohorts, FPG change was defined as the difference between baseline and last FPG, measured at the end of follow-up in IT-DIAB and at the 4-year visit in ELSA-Brasil. We use univariable and multivariable linear regression to assess the association between PCSK9 and FPG change. The parameters considered as potential confounders before stepwise selection were the same as in the Cox model above. We also used fractional polynomial transformation to capture a possible non-linear effect of the exposure, with a model selection threshold fixed to 0.20 , but only linear models were withheld by this approach [21].

Sensitivity analyses were performed in a subset of the ELSA-Brasil cohort with prediabetes at baseline. Particularly, correlations between baseline PCSK9 and changes in FPG between baseline and 4-year visit were determined. 
A $P$-value $<0.05$ was deemed statistically significant. All statistical analyses were performed using $\mathrm{R}$ software version 3.5.1 with Rstudio interface (The R Foundation for Statistical Computing, R Core Team 2018, Vienna, Austria).

\section{RESULTS}

\section{Baseline characteristics of study participants}

Study population characteristics at baseline in ELSA-Brasil and IT-DIAB cohorts are reported in Table 1. The analytical study population was on average middle aged (mean \pm SD: $56.3 \pm$ 9.8 and $50.4 \pm 8.4$ years in IT-DIAB and ELSA-Brasil, respectively) and overweight (mean $\mathrm{BMI} \pm \mathrm{SD}: 29.7 \pm 6.3$ and $26.9 \pm 4.6 \mathrm{~kg} / \mathrm{m}^{2}$ in IT-DIAB and ELSA-Brasil, respectively). In ITDIAB, all participants had prediabetes at baseline with IFG (mean FPG \pm SD: $115.7 \pm 4.4$ $\mathrm{mg} / \mathrm{dL}$ ); compared to only $27.5 \%$ (482/1751) in ELSA-Brasil (mean FPG \pm SD: $101.0 \pm 6.1$

$\mathrm{mg} / \mathrm{dL}$ ). The selected participants of both cohorts were not under statin therapy. Plasma lipid parameters were in the normal range with mean $( \pm$ SD) LDL-C concentrations of $143 \pm 35$ and $134 \pm 33 \mathrm{mg} / \mathrm{dL}$ in IT-DIAB and ELSA-Brasil, respectively. Baseline characteristics of the two populations according to diabetes status (NOD vs no NOD) at the final visit are shown in supplementary Table 1. Baseline plasma PCSK9 levels were lower in IT-DIAB $(260 \pm 95$ $\mathrm{ng} / \mathrm{mL})$ than in ELSA-Brasil $(319 \pm 83 \mathrm{ng} / \mathrm{mL})$ (Table 1). The histograms of baseline fasting plasma PCSK9 level distribution according to diabetes status at the end of follow-up in both cohorts did not highlight obvious differences between groups (Supplementary Fig. 2).

\section{Plasma PCSK9 levels and risk of NOD during follow-up}

After 5 years of follow-up in IT-DIAB, $36.9 \%$ of participants $(86 / 233)$ converted to NOD. The Kaplan-Meier survival curves showed that plasma PCSK9 levels (classified as quartiles) was not associated with the risk of conversion to $\operatorname{NOD}(P=0.87$, log-rank test) (Figure 1). Similar 
results were obtained when using tertiles of plasma PCSK9 levels $(P=0.93$, log-rank test; data not shown). In Cox models using a continuous approach, baseline plasma PCSK9 levels were not associated with NOD during the follow-up, both before and after adjustment (HR [+1 SD] $=0.93, \mathrm{CI}_{95 \%}[0.74 ; 1.15]$ and $0.96[0.76 ; 1.21]$, respectively) (Table 2). After stepwise selection, factors associated with the risk of conversion to NOD were the waist circumference, FPG and fasting TG. In ELSA-Brasil, 3.9\% (69/1751) of participants developed NOD at the second visit at 4 years. As in IT-DIAB, plasma PCSK9 levels were not associated with the risk of NOD neither in univariate nor in multivariable logistic regression: OR $(+1 \mathrm{SD})=1.17$ [0.93; 1.47] $(P=0.18)$ and $1.13[0.89 ; 1.41](P=0.31)$, respectively. A multivariable approach adjusted on the same parameters as IT-DIAB's Cox model demonstrated that waist circumference $(\mathrm{OR}(+1 \mathrm{SD})=1.33[1.04 ; 1.70], P=0.024)$ and $\mathrm{FPG}(\mathrm{OR}(+1 \mathrm{SD})=1.79[1.41$; 2.28], $P<0.0001)$ were associated with the risk of NOD, while TG did not reach statistical significance $(\mathrm{OR}(+1 \mathrm{SD})=1.17[0.97 ; 1.37], P=0.064)$. Furthermore, when considering the combined event of worsening of glucose homeostasis (i.e. progression from normoglycemia to prediabetes or NOD and progression from prediabetes to NOD), we found a significant positive association with PCSK9 in both univariate and multivariable approaches: OR $(+1 \mathrm{SD})=1.18$ $[1.06 ; 1.32](P=0.0031)$ and $1.17[1.04 ; 1.30](P=0.0074)$, respectively.

\section{Cross-sectional associations between plasma PCSK9 levels and metabolic parameters}

Spearman's rank correlations were assessed between plasma PCSK9 and metabolic parameters at baseline (Table 1). Plasma PCSK9 levels were positively associated with total cholesterol in both IT-DIAB $(\mathrm{r}=0.17 ; P=0.009)$ and ELSA-Brasil $(\mathrm{r}=0.09 ; P=0.0003)$. Significant positive associations were also found between PCSK9 and LDL-C $(\mathrm{r}=0.08 ; P=0.001), \mathrm{TG}(\mathrm{r}=0.08$; $P=0.002)$ and ApoB $(\mathrm{r}=0.08 ; P=0.0008)$ in ELSA-Brasil. Regarding glucose homeostasis parameters, plasma PCSK9 was not associated with either FPG or A1C. A small but significant, 
correlation was found between PCSK9 and HOMA-IR $(\mathrm{r}=0.06, P=0.01)$ in ELSA-Brasil, close from the correlation found in IT-DIAB $(\mathrm{r}=0.05 ; P=0.49)$.

\section{Association between baseline PCSK9 levels and changes in FPG}

In IT-DIAB, the linear regression models showed no statistically significant association between baseline PCSK9 and FPG change at the end of the follow-up: $\beta$ (for 1 SD of FPG change / 1 SD of baseline PCSK9) $=-0.065[-0.197 ; 0.067](P=0.34)$ and $-0.038[-0.17 ; 0.09]$ $(P=0.57)$, in univariate and multivariable analyses, respectively. Using the same approach in ELSA-Brasil, a significant positive association was found with a $\beta$ (for 1 SD of FPG change / 1 SD of baseline PCSK9) $=0.052[0.006 ; 0.099](P=0.029)$ and $0.053[0.006 ; 0.010](P=$ 0.026), in univariate and multivariable analyses, respectively (Table 3 ). In a sensitivity analysis focused on the ELSA-Brasil population with prediabetes $(n=482)$, the observed association between baseline PCSK9 and FPG change was of greater magnitude but not significant: $\beta=$ $0.076[-0.058 ; 0.21](P=0.27)$ in univariate and $0.068[-0.066 ; 0.202](P=0.30)$ in multivariable analysis.

\section{DISCUSSION}

Mainly based on Mendelian randomisation studies, a doubt has emerged about the potential diabetogenic risk of PCSK9 inhibitors. Here, we demonstrate that circulating PCSK9 concentrations are not significantly associated with the risk of NOD in two independent longitudinal cohorts, and most notably in individuals with prediabetes at high risk of conversion to type 2 diabetes. In the larger cohort (ELSA-Brasil), we even found that baseline PCSK9 levels were rather positively associated with a slight risk of worsening of glucose homeostasis, since (i) elevated PCSK9 levels were associated with an increased risk of conversion from normoglycemia to prediabetes or NOD and from prediabetes to NOD, and since (ii) there was 
a small but significant positive association between PCSK9 levels and FPG change during follow-up. All together, these data indicate that inhibiting circulating PCSK9 with PCSK9 mAb might not be deleterious for glucose homeostasis.

Our findings are consistent with the results of large cardiovascular outcomes randomized clinical trials (RCTs) with PCSK9 mAb that found that neither evolocumab nor alirocumab were associated with an increased risk of NOD, even while the duration of follow-up remains quite short $(<3$ years) [22,23]. Similar reassuring results were also obtained in pooled analyses of phase 3 trials $[24,25]$. Of note, a recent meta-analysis including more than 68,000 participants in 20 RCTs with a median follow-up of 78 weeks found that PCSK9 mAb modestly increased FPG $(<2.0 \mathrm{mg} / \mathrm{dL})$ and A1C $(<0.05 \%)$ when compared with placebo, without increasing the risk of NOD [26].

Our results are also consistent with some pre-clinical findings regarding the molecular link between PCSK9 and diabetes [27]. Using transgenic mouse models, Da Dalt et al recently demonstrated that intra-cellular PCSK9 rather that circulating PCSK9 is involved in the regulation of glucose homeostasis. Indeed, while total PCSK9 knockout mice exhibit impaired glucose tolerance and reduced insulin secretion, liver-specific PCSK9 knockout mice, that retain PCSK9 expression in extrahepatic organs and do not have detectable PCSK9 in their blood, show normal glycemic parameters [12]. In addition, we previously demonstrated that recombinant PCSK9 is able to drastically down-regulate the LDLR expression in human and mouse primary pancreatic islets [13]. While LDLR expression is increased in pancreatic islets from total PCSK9 knockout mice, there is no alteration in glucose-stimulated insulin secretion, even in the presence of high LDL concentrations [13]. This lack of deleterious effect of PCSK9deficiency on insulin secretion ex vivo is associated to the absence of change in intra-cellular cholesterol content in the islets. Such a discrepancy between the increased LDLR expression and the normal islets cholesterol content remains unclear. Given that PCSK9 is able to inhibit 
ATP binding cassette transporter A1 mediated cholesterol efflux in macrophages [28], it cannot be ruled out that PCSK9-deficiency may increase cholesterol efflux from the islets, a key factor of beta cell cholesterol homeostasis [29]. In addition, the effect of PCSK9-deficiency on glucose homeostasis may not be restricted to pancreatic islets [30]. For instance, individuals carrying the PCSK9 R46L LOF variant have higher BMI, and increased body and liver fat mass percentage compared to controls [31]. The underlying mechanisms underpinning the potential increased risk of diabetes associated with PCSK9 deficiency or PCSK9 LOF variants remains to be investigated.

In the larger cohort (ELSA-Brasil), baseline plasma PCSK9 concentrations were positively associated with FPG change at 4-year. Even if the correlation is weak (an increase of about 0.05 SD (0.01-0.10) of FPG for 1 SD of PCSK9), this observation suggests that PCSK9 expression may be driven by a common feature of the metabolic syndrome such as insulin resistance. Previous transversal analyses in several cohorts highlighted a relationship between plasma PCSK9 levels and markers of glucose homeostasis. Higher plasma PCSK9 levels have been observed in patients with type 2 diabetes compared with non-diabetic individuals in most studies [32-36], but not all [37]. Circulating PCSK9 levels positively correlated with FPG, fasting plasma insulin, HOMA-IR, and A1C in several cohorts [32,38-40]. Moreover, plasma PCSK9 concentrations increased after short-term high-fructose diet and correlated with hepatic insulin sensitivity assessed by hyperinsulinemic-euglycemic clamp in healthy volunteers [41]. In agreement with these findings, a positive correlation between PCSK9 and HOMA-IR was found in ELSA-Brasil.

One of the strengths of our study is that we obtained consistent results in two independent cohorts with different population sizes and ethnicities $(n=233$ for IT-DIAB and $n=1751$ for ELSA-Brasil), baseline plasma PCSK9 levels (higher in ELSA-Brasil than in IT-DIAB) and NOD risk levels $(36.9 \%$ at 5 -years for IT-DIAB and 3.9\% at 4-years for ELSA-Brasil). In 
addition, plasma PCSK9 levels were assessed using a standardized protocol using the same assay throughout. Participants under statin therapy, an important confounding factor for PCSK9 levels, were also excluded [42]. Our study presents however some limitations. In both cohorts, there were no repeated measures of circulating PCSK9 to investigate its relationship with glucose homeostasis parameters during follow-up. In IT-DIAB, no systematic OGTT was performed during the annual visit, in addition to FPG and A1C, to diagnose NOD. In ELSABrasil there was no repeated measure of FPG between baseline and 4-years to draw survival curves as in IT-DIAB. The observational nature of our study only allows to draw some associations regarding PCSK9 role in conversion to type 2 diabetes, but no causation. Due to a potential lack of statistical power, the absence of a diabetogenic effect for PCSK9 in our study is not definitive evidence for the absence of a role PCSK9 in glucose homeostasis.

In conclusion, this study assessed for the first time the association between circulating PCSK9 levels and the risk of diabetes in longitudinal analyses. Our data indicate that plasma PCSK9 levels do not predict the risk of conversion to type 2 diabetes in patients with prediabetes and are reassuring regarding the safety of PCSK9 mAb that specifically target the extra-cellular PCSK9 pathway. 


\section{CONFLICT OF INTEREST}

RDS has received research funding, honoraria, and consulting fees from Amgen, Merck, Astra Zeneca, Eli Lilly, Sanofi-Regeneron, Boehringher Ingelheim, Kowa, and Pfizer. GL has received research funding, honoraria, and consulting fees from Sanofi-Regeneron, Amgen, Affiris, Nyrada, and Pfizer. BC has received research funding, honoraria and consulting fees from Sanofi-Regeneron Pfizer, Amgen, and MSD. All other authors have nothing to disclose.

\section{FINANCIAL SUPPORT}

IT-DIAB was funded by an ISI grant from OSEO-API, France to Genfit (coordinator of ITDiab consortium) and CHU de Nantes, France. This work was supported by the French national project CHOPIN (CHolesterol Personalized INnovation) funded by the Agence Nationale de la Recherche (ANR-16-RHUS-0007) and coordinated by the CHU of Nantes. VB is a recipient of a scholarship from La Région Réunion and the European Union (European Regional Development Fund INTERREG V) - RDS is a recipient of a scholarship from the Conselho Nacional de Pesquisa e Desenvolvimento Tecnologico (CNPq) process \# 303734/2018-3.

\section{AUTHOR CONTRIBUTIONS}

SRM researched data and wrote the manuscript. MW performed the statistical analyses and wrote the manuscript. MP, CLM, AT, VB, BN RDS, IMB, and PAL researched data and reviewed/edited the manuscript. GL and BC supervised the work, wrote the manuscript and handled funding. 


\section{REFERENCES}

[1] N. Sattar, D. Preiss, H.M. Murray, P. Welsh, B.M. Buckley, A.J.M. de Craen, S.R.K. Seshasai, J.J. McMurray, D.J. Freeman, J.W. Jukema, P.W. Macfarlane, C.J. Packard, D.J. Stott, R.G. Westendorp, J. Shepherd, B.R. Davis, S.L. Pressel, R. Marchioli, R.M. Marfisi, A.P. Maggioni, L. Tavazzi, G. Tognoni, J. Kjekshus, T.R. Pedersen, T.J. Cook, A.M. Gotto, M.B. Clearfield, J.R. Downs, H. Nakamura, Y. Ohashi, K. Mizuno, K.K. Ray, I. Ford, Statins and risk of incident diabetes: a collaborative meta-analysis of randomised statin trials, Lancet. 375 (2010) 735-742. doi:10.1016/S01406736(09)61965-6.

[2] D. Preiss, S.R.K. Seshasai, P. Welsh, S.A. Murphy, J.E. Ho, D.D. Waters, D.A. DeMicco, P. Barter, C.P. Cannon, M.S. Sabatine, E. Braunwald, J.J.P. Kastelein, J.A. de Lemos, M.A. Blazing, T.R. Pedersen, M.J. Tikkanen, N. Sattar, K.K. Ray, Risk of incident diabetes with intensive-dose compared with moderate-dose statin therapy: a meta-analysis, JAMA. 305 (2011) 2556-2564. doi:10.1001/jama.2011.860.

[3] E.P. Navarese, A. Buffon, F. Andreotti, M. Kozinski, N. Welton, T. Fabiszak, S. Caputo, G. Grzesk, A. Kubica, I. Swiatkiewicz, A. Sukiennik, M. Kelm, S. De Servi, J. Kubica, Meta-analysis of impact of different types and doses of statins on new-onset diabetes mellitus, Am. J. Cardiol. 111 (2013) 1123-1130. doi:10.1016/j.amjcard.2012.12.037.

[4] C.R. Dormuth, K.B. Filion, J.M. Paterson, M.T. James, G.F. Teare, C.B. Raymond, E. Rahme, H. Tamim, L. Lipscombe, Canadian Network for Observational Drug Effect Studies Investigators, Higher potency statins and the risk of new diabetes: multicentre, observational study of administrative databases, BMJ. 348 (2014) g3244. doi:10.1136/bmj.g3244.

[5] P. Kohli, D.D. Waters, R. Nemr, B.J. Arsenault, M. Messig, D.A. DeMicco, R. Laskey, J.J.P. Kastelein, Risk of new-onset diabetes and cardiovascular risk reduction from highdose statin therapy in pre-diabetics and non-pre-diabetics: an analysis from TNT and IDEAL, J. Am. Coll. Cardiol. 65 (2015) 402-404. doi:10.1016/j.jacc.2014.10.053.

[6] D.I. Swerdlow, D. Preiss, Genetic insights into statin-associated diabetes risk, Curr. Opin. Lipidol. 27 (2016) 125-130. doi:10.1097/MOL.0000000000000272.

[7] J. Besseling, J.J.P. Kastelein, J.C. Defesche, B.A. Hutten, G.K. Hovingh, Association between familial hypercholesterolemia and prevalence of type 2 diabetes mellitus, JAMA. 313 (2015) 1029-1036. doi:10.1001/jama.2015.1206.

[8] G. Lambert, B. Sjouke, B. Choque, J.J.P. Kastelein, G.K. Hovingh, The PCSK9 decade, J. Lipid Res. 53 (2012) 2515-2524. doi:10.1194/jlr.R026658.

[9] E.F. Villard, A. Thedrez, J. Blankenstein, M. Croyal, T.-T.-T. Tran, B. Poirier, J.-C. Le Bail, S. Illiano, E. Nobécourt, M. Krempf, D.J. Blom, A.D. Marais, P. Janiak, A.J. Muslin, E. Guillot, G. Lambert, PCSK9 Modulates the Secretion But Not the Cellular Uptake of Lipoprotein(a) Ex Vivo: An Effect Blunted by Alirocumab, JACC Basic Transl Sci. 1 (2016) 419-427. doi:10.1016/j.jacbts.2016.06.006.

[10] A. Thedrez, D.J. Blom, S. Ramin-Mangata, V. Blanchard, M. Croyal, K. Chemello, B. Nativel, M. Pichelin, B. Cariou, S. Bourane, L. Tang, M. Farnier, F.J. Raal, G. Lambert, Homozygous Familial Hypercholesterolemia Patients With Identical Mutations Variably Express the LDLR (Low-Density Lipoprotein Receptor): Implications for the Efficacy of Evolocumab, Arterioscler. Thromb. Vasc. Biol. 38 (2018) 592-598. doi:10.1161/ATVBAHA.117.310217.

[11] M. Mbikay, F. Sirois, J. Mayne, G.-S. Wang, A. Chen, T. Dewpura, A. Prat, N.G. Seidah, M. Chretien, F.W. Scott, PCSK9-deficient mice exhibit impaired glucose tolerance and pancreatic islet abnormalities, FEBS Lett. 584 (2010) 701-706. doi:10.1016/j.febslet.2009.12.018. 
[12] L. Da Dalt, M. Ruscica, F. Bonacina, G. Balzarotti, A. Dhyani, E. Di Cairano, A. Baragetti, L. Arnaboldi, S. De Metrio, F. Pellegatta, L. Grigore, M. Botta, C. Macchi, P. Uboldi, C. Perego, A.L. Catapano, G.D. Norata, PCSK9 deficiency reduces insulin secretion and promotes glucose intolerance: the role of the low-density lipoprotein receptor, Eur. Heart J. (2018). doi:10.1093/eurheartj/ehy357.

[13] C. Langhi, C. Le May, V. Gmyr, B. Vandewalle, J. Kerr-Conte, M. Krempf, F. Pattou, P. Costet, B. Cariou, PCSK9 is expressed in pancreatic delta-cells and does not alter insulin secretion, Biochem. Biophys. Res. Commun. 390 (2009) 1288-1293. doi:10.1016/j.bbrc.2009.10.138.

[14] L.A. Lotta, S.J. Sharp, S. Burgess, J.R.B. Perry, I.D. Stewart, S.M. Willems, J. Luan, E. Ardanaz, L. Arriola, B. Balkau, H. Boeing, P. Deloukas, N.G. Forouhi, P.W. Franks, S. Grioni, R. Kaaks, T.J. Key, C. Navarro, P.M. Nilsson, K. Overvad, D. Palli, S. Panico, J.-R. Quirós, E. Riboli, O. Rolandsson, C. Sacerdote, E.C. Salamanca, N. Slimani, A.M. Spijkerman, A. Tjonneland, R. Tumino, D.L. van der A, Y.T. van der Schouw, M.I. McCarthy, I. Barroso, S. O'Rahilly, D.B. Savage, N. Sattar, C. Langenberg, R.A. Scott, N.J. Wareham, Association Between Low-Density Lipoprotein Cholesterol-Lowering Genetic Variants and Risk of Type 2 Diabetes: A Meta-analysis, JAMA. 316 (2016) 1383-1391. doi:10.1001/jama.2016.14568.

[15] A.F. Schmidt, D.I. Swerdlow, M.V. Holmes, R.S. Patel, Z. Fairhurst-Hunter, D.M. Lyall, F.P. Hartwig, B.L. Horta, E. Hyppönen, C. Power, M. Moldovan, E. van Iperen, G.K. Hovingh, I. Demuth, K. Norman, E. Steinhagen-Thiessen, J. Demuth, L. Bertram, T. Liu, S. Coassin, J. Willeit, S. Kiechl, K. Willeit, D. Mason, J. Wright, R. Morris, G. Wanamethee, P. Whincup, Y. Ben-Shlomo, S. McLachlan, J.F. Price, M. Kivimaki, C. Welch, A. Sanchez-Galvez, P. Marques-Vidal, A. Nicolaides, A.G. Panayiotou, N.C. Onland-Moret, Y.T. van der Schouw, G. Matullo, G. Fiorito, S. Guarrera, C. Sacerdote, N.J. Wareham, C. Langenberg, R. Scott, J. Luan, M. Bobak, S. Malyutina, A. Pająk, R. Kubinova, A. Tamosiunas, H. Pikhart, L.L.N. Husemoen, N. Grarup, O. Pedersen, T. Hansen, A. Linneberg, K.S. Simonsen, J. Cooper, S.E. Humphries, M. Brilliant, T. Kitchner, H. Hakonarson, D.S. Carrell, C.A. McCarty, H.L. Kirchner, E.B. Larson, D.R. Crosslin, M. de Andrade, D.M. Roden, J.C. Denny, C. Carty, S. Hancock, J. Attia, E. Holliday, M. O’Donnell, S. Yusuf, M. Chong, G. Pare, P. van der Harst, M.A. Said, R.N. Eppinga, N. Verweij, H. Snieder, LifeLines Cohort study group, T. Christen, D.O. Mook-Kanamori, S. Gustafsson, L. Lind, E. Ingelsson, R. Pazoki, O. Franco, A. Hofman, A. Uitterlinden, A. Dehghan, A. Teumer, S. Baumeister, M. Dörr, M.M. Lerch, U. Völker, H. Völzke, J. Ward, J.P. Pell, D.J. Smith, T. Meade, A.H. Maitland-van der Zee, E.V. Baranova, R. Young, I. Ford, A. Campbell, S. Padmanabhan, M.L. Bots, D.E. Grobbee, P. Froguel, D. Thuillier, B. Balkau, A. Bonnefond, B. Cariou, M. Smart, Y. Bao, M. Kumari, A. Mahajan, P.M. Ridker, D.I. Chasman, A.P. Reiner, L.A. Lange, M.D. Ritchie, F.W. Asselbergs, J.-P. Casas, B.J. Keating, D. Preiss, A.D. Hingorani, UCLEB consortium, N. Sattar, PCSK9 genetic variants and risk of type 2 diabetes: a mendelian randomisation study, Lancet Diabetes Endocrinol. 5 (2017) 97-105. doi:10.1016/S2213-8587(16)30396-5.

[16] B.A. Ference, J.G. Robinson, R.D. Brook, A.L. Catapano, M.J. Chapman, D.R. Neff, S. Voros, R.P. Giugliano, G. Davey Smith, S. Fazio, M.S. Sabatine, Variation in PCSK9 and HMGCR and Risk of Cardiovascular Disease and Diabetes, N. Engl. J. Med. 375 (2016) 2144-2153. doi:10.1056/NEJMoa1604304.

[17] E.M.L. Aquino, S.M. Barreto, I.M. Bensenor, M.S. Carvalho, D. Chor, B.B. Duncan, P.A. Lotufo, J.G. Mill, M.D.C. Molina, E.L.A. Mota, V.M.A. Passos, M.I. Schmidt, M. Szklo, Brazilian Longitudinal Study of Adult Health (ELSA-Brasil): objectives and design, Am. J. Epidemiol. 175 (2012) 315-324. doi:10.1093/aje/kwr294. 
[18] M.I. Schmidt, P.A. Bracco, J.S. Yudkin, I.M. Bensenor, R.H. Griep, S.M. Barreto, C.D. Castilhos, B.B. Duncan, Intermediate hyperglycaemia to predict progression to type 2 diabetes (ELSA-Brasil): an occupational cohort study in Brazil, Lancet Diabetes Endocrinol. 7 (2019) 267-277. doi:10.1016/S2213-8587(19)30058-0.

[19] D.R. Matthews, J.P. Hosker, A.S. Rudenski, B.A. Naylor, D.F. Treacher, R.C. Turner, Homeostasis model assessment: insulin resistance and beta-cell function from fasting plasma glucose and insulin concentrations in man, Diabetologia. 28 (1985) 412-419.

[20] M. Croyal, F. Fall, M. Krempf, A. Thédrez, K. Ouguerram, V. Ferchaud-Roucher, A. Aguesse, S. Billon-Crossouard, P. Mata, R. Alonso, G. Lambert, E. Nobécourt, Plasma PCSK9 measurement by liquid chromatography-Tandem mass spectrometry and comparison with conventional ELISA, J. Chromatogr. B Analyt. Technol. Biomed. Life Sci. 1044-1045 (2017) 24-29. doi:10.1016/j.jchromb.2016.12.040.

[21] W. Sauerbrei, C. Meier-Hirmer, A. Benner, P. Royston, Multivariable regression model building by using fractional polynomials: Description of SAS, STATA and R programs, Computational Statistics \& Data Analysis. 50 (2006) 3464-3485. doi:10.1016/j.csda.2005.07.015.

[22] M.S. Sabatine, R.P. Giugliano, A.C. Keech, N. Honarpour, S.D. Wiviott, S.A. Murphy, J.F. Kuder, H. Wang, T. Liu, S.M. Wasserman, P.S. Sever, T.R. Pedersen, FOURIER Steering Committee and Investigators, Evolocumab and Clinical Outcomes in Patients with Cardiovascular Disease, N. Engl. J. Med. 376 (2017) 1713-1722. doi:10.1056/NEJMoa1615664.

[23] G.G. Schwartz, P.G. Steg, M. Szarek, D.L. Bhatt, V.A. Bittner, R. Diaz, J.M. Edelberg, S.G. Goodman, C. Hanotin, R.A. Harrington, J.W. Jukema, G. Lecorps, K.W. Mahaffey, A. Moryusef, R. Pordy, K. Quintero, M.T. Roe, W.J. Sasiela, J.-F. Tamby, P. Tricoci, H.D. White, A.M. Zeiher, Alirocumab and Cardiovascular Outcomes after Acute Coronary Syndrome, New England Journal of Medicine. 379 (2018) 2097-2107. doi:10.1056/NEJMoa1801174.

[24] H.M. Colhoun, H.N. Ginsberg, J.G. Robinson, L.A. Leiter, D. Müller-Wieland, R.R. Henry, B. Cariou, M.T. Baccara-Dinet, R. Pordy, L. Merlet, R.H. Eckel, No effect of PCSK9 inhibitor alirocumab on the incidence of diabetes in a pooled analysis from 10 ODYSSEY Phase 3 studies, Eur. Heart J. 37 (2016) 2981-2989. doi:10.1093/eurheartj/ehw292.

[25] N. Sattar, P.P. Toth, D.J. Blom, M.J. Koren, H. Soran, M. Uhart, M. Elliott, M. Cyrille, R. Somaratne, D. Preiss, Effect of the Proprotein Convertase Subtilisin/Kexin Type 9 Inhibitor Evolocumab on Glycemia, Body Weight, and New-Onset Diabetes Mellitus, Am. J. Cardiol. 120 (2017) 1521-1527. doi:10.1016/j.amjcard.2017.07.047.

[26] L.S.F. de Carvalho, A.M. Campos, A.C. Sposito, Proprotein Convertase Subtilisin/Kexin Type 9 (PCSK9) Inhibitors and Incident Type 2 Diabetes: A Systematic Review and Meta-analysis With Over 96,000 Patient-Years, Diabetes Care. 41 (2018) 364-367. doi:10.2337/dc17-1464.

[27] W. Dijk, B. Cariou, Efficacy and safety of proprotein convertase subtilisin/kexin 9 inhibitors in people with diabetes and dyslipidaemia, Diabetes, Obesity and Metabolism. 21 (2019) 39-51. doi:10.1111/dom.13636.

[28] M.P. Adorni, E. Cipollari, E. Favari, I. Zanotti, F. Zimetti, A. Corsini, C. Ricci, F. Bernini, N. Ferri, Inhibitory effect of PCSK9 on Abca1 protein expression and cholesterol efflux in macrophages, Atherosclerosis. 256 (2017) 1-6. doi:10.1016/j.atherosclerosis.2016.11.019.

[29] L.R. Brunham, J.K. Kruit, T.D. Pape, J.M. Timmins, A.Q. Reuwer, Z. Vasanji, B.J. Marsh, B. Rodrigues, J.D. Johnson, J.S. Parks, C.B. Verchere, M.R. Hayden, Beta-cell 
ABCA1 influences insulin secretion, glucose homeostasis and response to thiazolidinedione treatment, Nat. Med. 13 (2007) 340-347. doi:10.1038/nm1546.

[30] R.M. Stoekenbroek, G. Lambert, B. Cariou, G.K. Hovingh, Inhibiting PCSK9 - biology beyond LDL control, Nat Rev Endocrinol. 15 (2018) 52-62. doi:10.1038/s41574-0180110-5.

[31] A. Baragetti, G. Balzarotti, L. Grigore, F. Pellegatta, U. Guerrini, G. Pisano, A.L. Fracanzani, S. Fargion, G.D. Norata, A.L. Catapano, PCSK9 deficiency results in increased ectopic fat accumulation in experimental models and in humans, Eur J Prev Cardiol. 24 (2017) 1870-1877. doi:10.1177/2047487317724342.

[32] S.G. Lakoski, T.A. Lagace, J.C. Cohen, J.D. Horton, H.H. Hobbs, Genetic and Metabolic Determinants of Plasma PCSK9 Levels, J Clin Endocrinol Metab. 94 (2009) 2537-2543. doi:10.1210/jc.2009-0141.

[33] Y. Nekaies, B. Baudin, M. Sakly, N. Attia, Plasma proprotein convertase subtilisin/kexin type 9 (PCSK9) is associated with Lp(a) in type 2 diabetic patients, Atherosclerosis. 241 (2015) e102. doi:10.1016/j.atherosclerosis.2015.04.356.

[34] D. Ibarretxe, J. Girona, N. Plana, A. Cabré, R. Ferré, N. Amigó, S. Guaita, R. Mallol, M. Heras, L. Masana, Circulating PCSK9 in patients with type 2 diabetes and related metabolic disorders, Clin Investig Arterioscler. 28 (2016) 71-78. doi:10.1016/j.arteri.2015.11.001.

[35] B. Cariou, M. Le Bras, C. Langhi, C. Le May, B. Guyomarc'h-Delasalle, M. Krempf, P. Costet, Association between plasma PCSK9 and gamma-glutamyl transferase levels in diabetic patients, Atherosclerosis. 211 (2010) 700-702. doi:10.1016/j.atherosclerosis.2010.04.015.

[36] B.J. Arsenault, F. Petrides, F. Tabet, W. Bao, G.K. Hovingh, S.M. Boekholdt, S. RaminMangata, O. Meilhac, D. DeMicco, K.-A. Rye, D.D. Waters, J.J.P. Kastelein, P. Barter, G. Lambert, Effect of atorvastatin, cholesterol ester transfer protein inhibition, and diabetes mellitus on circulating proprotein subtilisin kexin type 9 and lipoprotein(a) levels in patients at high cardiovascular risk, J Clin Lipidol. 12 (2018) 130-136. doi:10.1016/j.jacl.2017.10.001.

[37] M.C.G.J. Brouwers, J.S. Troutt, M.M.J. van Greevenbroek, I. Ferreira, E.J. Feskens, C.J.H. van der Kallen, N.C. Schaper, C.G. Schalkwijk, R.J. Konrad, C.D.A. Stehouwer, Plasma proprotein convertase subtilisin kexin type 9 is not altered in subjects with impaired glucose metabolism and type 2 diabetes mellitus, but its relationship with nonHDL cholesterol and apolipoprotein B may be modified by type 2 diabetes mellitus: The CODAM study, Atherosclerosis. 217 (2011) 263-267.

doi:10.1016/j.atherosclerosis.2011.03.023.

[38] A. Baass, G. Dubuc, M. Tremblay, E.E. Delvin, J. O’Loughlin, E. Levy, J. Davignon, M. Lambert, Plasma PCSK9 is associated with age, sex, and multiple metabolic markers in a population-based sample of children and adolescents, Clin. Chem. 55 (2009) 16371645. doi:10.1373/clinchem.2009.126987.

[39] Q. Cui, X. Ju, T. Yang, M. Zhang, W. Tang, Q. Chen, Y. Hu, J.V. Haas, J.S. Troutt, R.T. Pickard, R. Darling, R.J. Konrad, H. Zhou, G. Cao, Serum PCSK9 is associated with multiple metabolic factors in a large Han Chinese population, Atherosclerosis. 213 (2010) 632-636. doi:10.1016/j.atherosclerosis.2010.09.027.

[40] C. Werner, M.M. Hoffmann, K. Winkler, M. Böhm, U. Laufs, Risk prediction with proprotein convertase subtilisin/kexin type 9 (PCSK9) in patients with stable coronary disease on statin treatment, Vascul. Pharmacol. 62 (2014) 94-102. doi:10.1016/j.vph.2014.03.004.

[41] B. Cariou, C. Langhi, M. Le Bras, M. Bortolotti, K.-A. Lê, F. Theytaz, C. Le May, B. Guyomarc'h-Delasalle, Y. Zaïr, R. Kreis, C. Boesch, M. Krempf, L. Tappy, P. Costet, 
Plasma PCSK9 concentrations during an oral fat load and after short term high-fat, highfat high-protein and high-fructose diets, Nutr Metab (Lond). 10 (2013) 4.

doi:10.1186/1743-7075-10-4

[42] P. Costet, M.M. Hoffmann, B. Cariou, B. Guyomarc'h Delasalle, T. Konrad, K. Winkler, Plasma PCSK9 is increased by fenofibrate and atorvastatin in a non-additive fashion in diabetic patients, Atherosclerosis. 212 (2010) 246-251. doi:10.1016/j.atherosclerosis.2010.05.027. 


\section{TABLES}

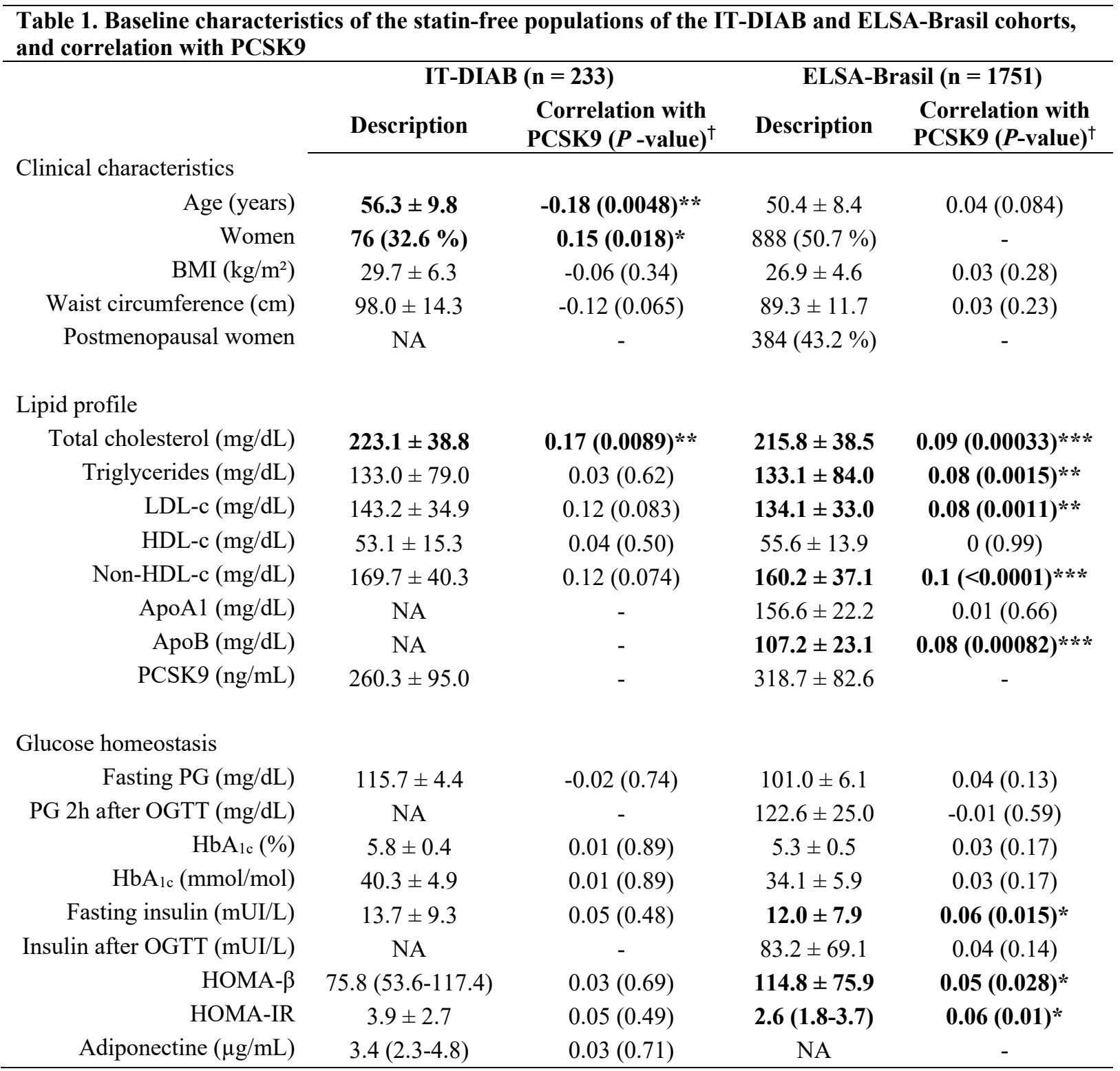

Table 1 - Baseline characteristics of the statin-free populations of the IT-DIAB and ELSA-

Brasil cohorts, and correlation with PCSK9 - Data are presented using size (\%), mean \pm standard deviation or median $\left(25^{\text {th }}-75^{\text {th }}\right.$ centiles $)$. ApoA1: Apolipoprotein A1; ApoB: Apolipoprotein B; HOMA-IR: Homeostasis Model Assessment of Insulin Resistance; NA: data not available; OGTT: oral-glucose tolerance test; PG: plasma glucose. * $p$-value 0.01-0.05; ** $p$-value $0.001-0.01 ; * * * p$-value $<0.001 ;{ }^{\dagger}$ Correlation with PCSK9: Spearman's correlation coefficient. 


\begin{tabular}{|c|c|c|c|c|}
\hline & \multicolumn{2}{|c|}{$\begin{array}{c}\text { Univariable models } \\
\left(\mathrm{N}_{\max }=\mathbf{2 3 3}\right)\end{array}$} & \multicolumn{2}{|c|}{$\begin{array}{c}\text { Multivariable model } \\
(\mathbf{N}=\mathbf{2 1 0})\end{array}$} \\
\hline & HR (CI95\%) & p-value & HR (CI95\%) & p-value \\
\hline Age $(+1 S D)$ & $1.06[0.85 ; 1.33]$ & 0.62 & - & - \\
\hline Sex (women/men) & $1.11[0.71 ; 1.75]$ & 0.64 & - & - \\
\hline Waist circumference (+ 1SD) & $1.46[1.20 ; 1.79] * * *$ & 0.00021 & $1.45[1.16 ; 1.82]^{* *}$ & 0.0018 \\
\hline Fasting plasma glucose $(+1 S D)$ & $1.53[1.24 ; 1.89]^{* * *}$ & $<0.0001$ & $1.50[1.19 ; 1.88]^{* *}$ & 0.00038 \\
\hline Total cholesterol (+ 1SD) & $0.90[0.72 ; 1.12]$ & 0.34 & - & - \\
\hline Triglycerides $(+1 S D)$ & $1.15[0.96 ; 1.37]$ & 0.12 & $1.35[1.01 ; 1.79]^{*}$ & 0.039 \\
\hline$L D L-c(+1 S D)$ & $0.90[0.72 ; 1.12]$ & 0.34 & - & - \\
\hline$H D L-c(+1 S D)$ & $0.77[0.61 ; 0.98]^{*}$ & 0.033 & - & - \\
\hline Non-HDL-c $(+1 S D)$ & $0.98[0.79 ; 1.21]$ & 0.83 & - & - \\
\hline PCSK9 (+ 1SD) & $0.93[0.74 ; 1.15]$ & 0.49 & $0.96[0.76 ; 1.21]$ & 0.73 \\
\hline Adiponectin (+ $1 S D)$ & $0.75[0.57 ; 0.98]^{*}$ & 0.032 & - & - \\
\hline
\end{tabular}

Table 2 - Association between baseline characteristics and the risk of new onset diabetes during the follow-up. Cox proportional hazard model, univariate and multivariate analyses. IT-DIAB cohort $(\mathbf{N}=\mathbf{2 3 3})$ - Results obtained with Cox model based on the proportional hazard hypothesis. The main outcome was the occurrence of new onset diabetes, defined by a fasting $P G \geq 126 \mathrm{mg} / \mathrm{dL}$ and/or a $\mathrm{PG} \geq 200 \mathrm{mg} / \mathrm{dL}$ after 2-hour OGTT. Patients were right-censored after last follow-up, bariatric surgery, prescription of antidiabetic treatment or death, whatever came first. The baseline parameters included in the multivariable Cox model, before stepwise selection, were age, sex, waist circumference, triglycerides, LDL-c, HDL-c, adiponectin and PCSK9 levels, the latter being forced in the model. HR (95\% CI): Hazard-ratio with 95\% confidence interval; PG: plasma glucose. * $p$-value $0.01-0.05 ; * * p$-value $0.001-0.01$; $* * * p$-value $<0.001$. 


\begin{tabular}{|c|c|c|c|c|}
\hline \multirow[b]{4}{*}{ Age $(+1 S D)$} & \multicolumn{4}{|c|}{$\beta$ coefficient (CI95\%) } \\
\hline & \multicolumn{2}{|c|}{ Whole population } & \multicolumn{2}{|c|}{ Population with prediabetes } \\
\hline & $\begin{array}{c}\text { Univariate } \\
\left(\mathrm{N}_{\max }=1751\right)\end{array}$ & $\begin{array}{l}\text { Multivariate } \\
(\mathrm{n}=1720)\end{array}$ & $\begin{array}{c}\text { Univariate } \\
\left(\mathrm{N}_{\max }=482\right)\end{array}$ & $\begin{array}{l}\text { Multivariate } \\
(\mathrm{n}=475)\end{array}$ \\
\hline & $\begin{array}{c}-0.07 \\
{[-0.11 ;-0.02] * * * *}\end{array}$ & - & $\begin{array}{c}-0.13 \\
{[-0.26 ; 0.00]}\end{array}$ & - \\
\hline Sex (women/men) & $\begin{array}{c}-0.03 \\
{[-0.13 ; 0.06]}\end{array}$ & - & $\begin{array}{c}-0.03 \\
{[-0.31 ; 0.25]}\end{array}$ & - \\
\hline Waist circumference (+ 1SD) & $\begin{array}{c}0.10 \\
{[0.05 ; 0.14]^{* * *}}\end{array}$ & $\begin{array}{c}0.11 \\
{[0.06 ; 0.16]^{* * *}}\end{array}$ & $\begin{array}{c}0.14 \\
{[0.01 ; 0.28]^{*}}\end{array}$ & $\begin{array}{c}0.18 \\
{[0.05 ; 0.32]^{* *}}\end{array}$ \\
\hline Fasting $P G(+1 S D)$ & $\begin{array}{c}-0.12 \\
{[-0.16 ;-0.07]^{* * * *}}\end{array}$ & $\begin{array}{c}-0.14 \\
{[-0.19 ;-0.10]^{* * * *}}\end{array}$ & $\begin{array}{c}-0.12 \\
{[-0.22 ;-} \\
0.02]^{*}\end{array}$ & $\begin{array}{c}-0.15 \\
{[-0.26 ;-0.04]^{* * *}}\end{array}$ \\
\hline Total cholesterol (+ $1 S D)$ & $\begin{array}{c}0.00 \\
{[-0.05 ; 0.04]}\end{array}$ & - & $\begin{array}{c}0.01 \\
{[-0.13 ; 0.14]}\end{array}$ & \\
\hline Triglycerides $(+1 S D)$ & $\begin{array}{c}0.06 \\
{[0.01 ; 0.10]^{*}}\end{array}$ & - & $\begin{array}{c}0.07 \\
{[-0.05 ; 0.19]}\end{array}$ & - \\
\hline$L D L-c(+1 S D)$ & $\begin{array}{c}0.00 \\
{[-0.05 ; 0.05]}\end{array}$ & - & $\begin{array}{c}0.01 \\
{[-0.12 ; 0.15]}\end{array}$ & - \\
\hline$H D L-c(+1 S D)$ & $\begin{array}{c}-0.08 \\
{[-0.13 ;-0.03]^{* * *}}\end{array}$ & - & $\begin{array}{c}-0.13 \\
{[-0.27 ; 0.01]}\end{array}$ & - \\
\hline Non-HDL-c $(+1 S D)$ & $\begin{array}{c}0.03 \\
{[-0.02 ; 0.07]}\end{array}$ & - & $\begin{array}{c}0.06 \\
{[-0.08 ; 0.20]}\end{array}$ & - \\
\hline ApoAl (+ $1 S D)$ & $\begin{array}{c}-0.08 \\
{[-0.13 ;-0.03]^{* * * *}}\end{array}$ & $\begin{array}{c}-0.06 \\
{[-0.11 ;-0.01]^{*}}\end{array}$ & $\begin{array}{c}-0.15 \\
{[-0.30 ;-} \\
0.01]^{*}\end{array}$ & - \\
\hline$A p o B(+1 S D)$ & $\begin{array}{c}0.06 \\
{[0.01 ; 0.10]^{*}}\end{array}$ & - & $\begin{array}{c}0.12 \\
{[-0.02 ; 0.26]}\end{array}$ & - \\
\hline$P C S K 9(+1 S D)$ & $\begin{array}{c}0.05 \\
{[0.01 ; 0.10]^{*}}\end{array}$ & $\begin{array}{c}0.05 \\
{[0.01 ; 0.10]^{*}}\end{array}$ & $\begin{array}{c}0.08 \\
{[-0.06 ; 0.21]}\end{array}$ & $\begin{array}{c}0.07 \\
{[-0.06 ; 0.21]}\end{array}$ \\
\hline
\end{tabular}

Table 3 - Association between baseline PCSK9 levels and changes in fasting PG between baseline and $4^{\text {th }}$ year visit in the ELSA-Brasil cohort - All quantitative variables were expressed using Z-score. Therefore, the $\beta$ coefficient corresponds to the percentage of $1 \mathrm{SD}$ variation of fasting PG for an increase of $1 \mathrm{SD}$ of the studied parameter. $\beta$ coefficient associated with a $p$-value $<0.05$ are reported in bold. The following parameters were included in the multivariate regression model, before stepwise selection ( $\alpha$ threshold for the selection: 0.05 ): baseline age, sex, waist circumference, fasting PG, triglycerides, LDL-c, HDL-c, and PCSK9 (ApoB, ApoA1 and total cholesterol were not included because of the obvious colinearity with the other lipid parameters). ApoA1: Apolipoprotein A1; ApoB: Apolipoprotein B; PG: plasma glucose; SD: standard deviation. 


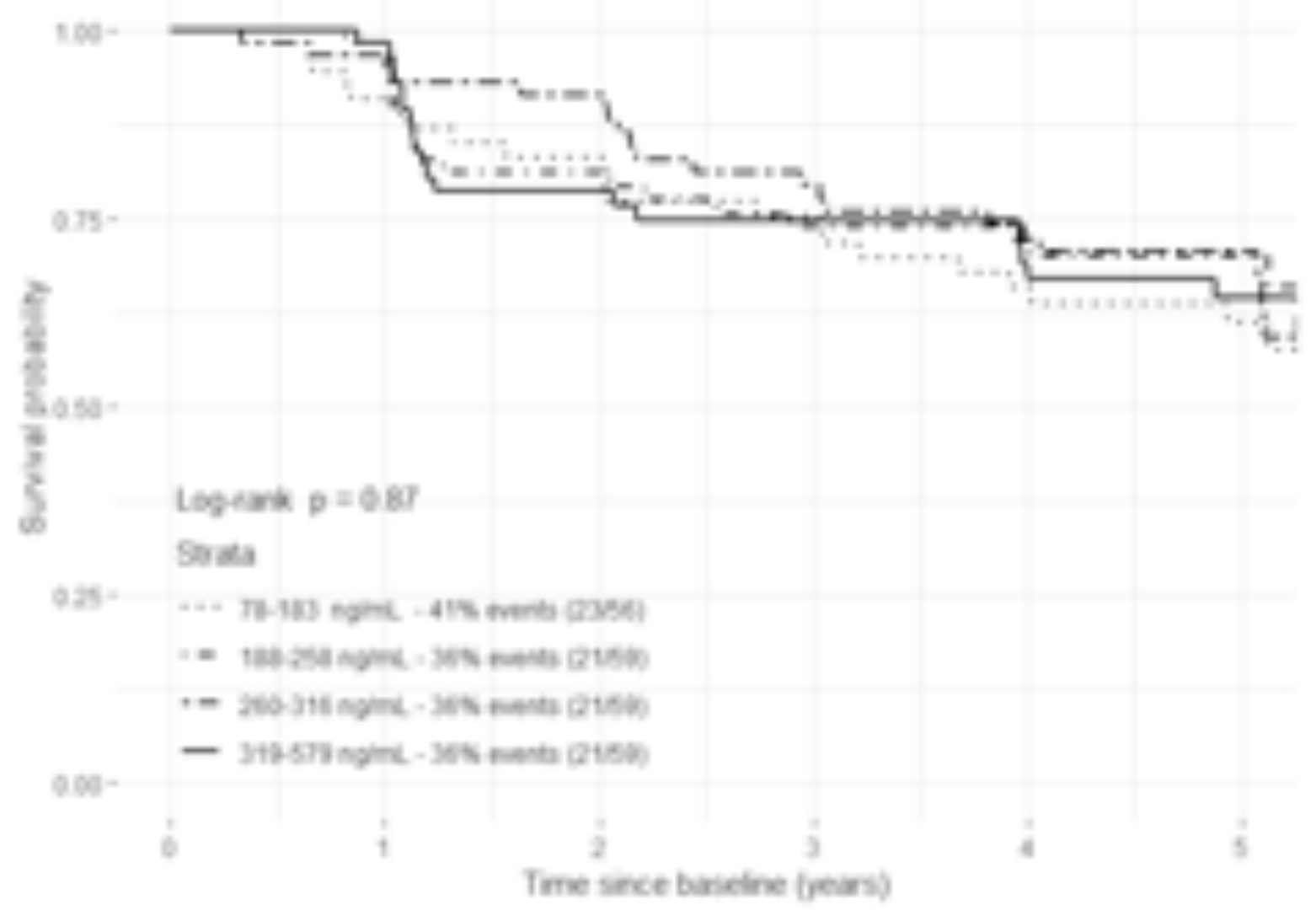

\section{Number at risk}

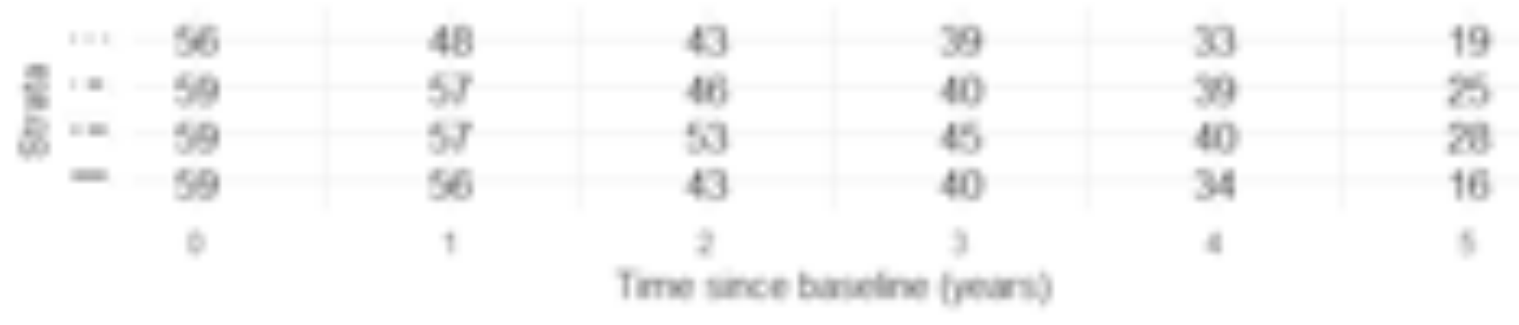

FIGURES LEGEND

Figure 1- Survival curves for New Onset Diabetes in the IT-DIAB cohort, according to baseline PCSK9 levels (groups created according to quartiles) - Dotted bar: lowest quartile for PCSK9 (78-183 ng/mL); Dot and dash bar: second quartile (188-258 ng/mL); Short and long dash: third quartile (260-316 ng/mL); Solid bar: highest quartile (319-579 ng/mL) 